\title{
Microstructure Development on Sintered Ti/HA Biocomposites Produced by Powder Metallurgy
}

Pedro Balbinotti, Enori Gemelli*, Gabriel Buerger ${ }^{\mathrm{a}}$, Sarah Amin de Lima ${ }^{\mathrm{a}}$,

Jailson de Jesus ${ }^{\mathrm{a}}$, Nelson Heriberto Almeida Camargo ${ }^{\text {a }}$

Vinicius André Rodrigues Henriques ${ }^{\mathrm{b}}$, Gloria Dulce de Almeida Soares ${ }^{\mathrm{c}}$

à Departamento de Engenharia Mecânica, Centro de Ciências Tecnológicas,

Universidade do Estado de Santa Catarina - UDESC, Campus Universitário,

Bairro Bom Retiro, CP 631, CEP 89223-100, Joinville, SC, Brazil

${ }^{\mathrm{b}}$ Centro Tecnológico Aeroespacial, Instituto de Aeronáutica e Espaço,

Praça Marechal-do-Ar Eduardo Gomes, 50, CEP 12228-904, São José dos Campos, SP, Brazil

'Instituto Alberto Luiz Coimbra de Pós-graduação e Pesquisa de Engenharia-COPPE,

Engenharia Metalúrgica e de Materiais, Universidade Federal do Rio de Janeiro - UFRJ,

CP 68505, CEP 21941-972, Rio de Janeiro, RJ, Brazil

Received: March 28, 2011; Revised: June 13, 2011

\begin{abstract}
Titanium-based composites with in-situ calcium and phosphor phases were prepared by powder metallurgy processing with titanium and hydroxyapatite (HA) powders. The mixtures were performed in a friction mill with alcohol for 5 hours, dried in a rotating evaporator, pressed at $600 \mathrm{MPa}$ and sintered at $1200{ }^{\circ} \mathrm{C}$ for 2 hours in argon atmosphere. Crystal phases of the as-fabricated composite are found to be, $\alpha-\mathrm{Ti}, \mathrm{CaTiO}_{3}, \mathrm{Ca}_{3}\left(\mathrm{PO}_{4}\right)_{2}$ and $\mathrm{Ti}_{\mathrm{x}} \mathrm{P}_{\mathrm{y}}$ phase(s). The analyses revealed that titanium particles were covered with a compact layer of $\mathrm{Ti}_{x} \mathrm{P}_{y}$ and $\mathrm{CaTiO}_{3}$ phases, which resulted from the decomposition of $\mathrm{HA}$ into $\mathrm{CaTiO}$ and $\beta-\mathrm{Ca}_{3}\left(\mathrm{PO}_{4}\right)_{2}$ at approximately $1025{ }^{\circ} \mathrm{C}$. Then the reactions were followed by the decomposition of $\beta-\mathrm{Ca}_{3}\left(\mathrm{PO}_{4}\right)_{2}$, resulting in the growth of $\mathrm{CaTiO}{ }_{3}$ layer and in the nucleation and growth of $\mathrm{Ti}_{\mathrm{x}} \mathrm{P}_{\mathrm{y}}$ phase(s).
\end{abstract}

Keywords: titanium, hydroxyapatite, composite, powder metallurgy

\section{Introduction}

Titanium has been widely used for biomedical applications under load-bearing conditions, due to its biocompatibility and low density coupled with good balance of mechanical properties and corrosion resistance ${ }^{1-5}$. However, titanium is a bioinert material, i.e. the interface between titanium and host bone is a simple interlocking bonding, which can lead to the loosening of the implant and the eventual failure of the implantation. Bone neoformation and long term stability can be achieved by using bioactive materials. Hydroxyapatite is the best option among bioactive materials, due to its chemical and crystallographic structure being similar to that of bone mineral ${ }^{6,7}$. This material has been successfully used as a bone substitute and for reconstitution in both orthopedic and dental fields. However, one of its primary restrictions on clinical use as a load-bearing implant is its poor mechanical properties ${ }^{8}$. A good combination of the bioactivity of hydroxyapatite and the mechanical properties of titanium is considered to be a promising approach to fabricating more suitable biomedical materials for load-bearing applications. This combination can be achieved by a powder metallurgy technique using appropriate mixtures of titanium and calcium phosphate powders. Many titanium composites containing hidroxiapatite, calcium phosphates or a mixture of varying contents of calcium and phosphorous compounds were synthesized through powder metallurgy under different processing conditions ${ }^{9-19}$. Although reporting densification and microstructure of biomaterials fabricated with various parameters, these investigations still cover a limited number of conditions such as raw materials, processing methods, particles size and their chemical and morphologic characteristics, which can lead to different results. Furthermore, the mechanical behavior of these composites has been rarely reported until now and further studies are needed for their applications in biomedical area. The biocomposites reported in the literature were produced with a high amount of $\mathrm{Ca}-\mathrm{P}$ compounds ( $>10 \%$ in volume), especially to study phase formation. In this study Ti-based composites were prepared with up to $10 \%$ in volume of hydroxyapatite (HA). Composites containing $10 \%$ of Ca-P compounds reportedly lead to the best results in terms of bioactive phases, density and strength ${ }^{19}$.

The purpose of this investigation was to evaluate the effect of hydroxyapatite particle size on the production, microstructure and compression strength of titanium/hydroxyapatite composites prepared by powder metallurgy. These biocomposites were obtained from mixtures containing micrometric $\mathrm{Ti}$ and either micrometric or nanometric hydroxyapatite powders. Biocomposites produced by powder metallurgy technique with titanium and nanometric HA powder were not found in the literature.

\section{Materials and Procedures}

\subsection{Raw materials}

The Ti powder, with particle size smaller than $150 \mu \mathrm{m}$, was supplied by TiBrasil company (Brazil) and the hydroxyapatite was produced by synthesis of calcium oxide and phosphoric acid 
( $85 \%$ pure) followed by thermal treatments. The calcium oxide was obtained by calcination of calcium carbonate $\left(99.8 \%\right.$ pure) at $900{ }^{\circ} \mathrm{C}$ for 2 hours. All reagents used in the synthesis were from VETEC Química Fina, Brazil.

\subsection{Synthesis of micrometric and nanometric $H A$}

Initially, calcium oxide $(\mathrm{CaO})$ was added to $500 \mathrm{~mL}$ of distilled water kept under mechanical stirring at approximately $300 \mathrm{rpm}$. After 2 hours, phosphoric acid $\left(\mathrm{H}_{3} \mathrm{PO}_{4}\right)$ was added drop by drop up to $\mathrm{Ca} / \mathrm{P}$ ratio of 1.67. The addition rate of the acid was approximately steady at $2 \mathrm{~mL} / \mathrm{min}$, while monitoring the solution $\mathrm{pH}$. Between 5 and 6 hours of stirring the $\mathrm{pH}$ dropped from approximately 11.2 to 8.5 , staying steady at this level up to the end of the process. After 24 hours of mechanical stirring the colloidal solution was placed inside a pear recipient and attached to a rotating evaporator in order to eliminate the water. The recovered material was ground manually in a mortar/ pestle and sieved through a mesh size of $100 \mu \mathrm{m}$. Then the nanometric powder was obtained by thermal treatment at $900{ }^{\circ} \mathrm{C}$ for 2 hours and the micrometric powder by thermal treatment at $1100^{\circ} \mathrm{C}$ for 2 hours in a furnace.

\subsection{Preparation of the composites and analysis}

The starting powders of Ti and HA were mixed in a friction mill with alcohol for 5 hours, dried in a rotating evaporator, pressed at $600 \mathrm{MPa}$ and sintered at $1200^{\circ} \mathrm{C}$ for 2 hours in an argon atmosphere. Disks of approximately $10 \mathrm{~mm}$ in diameter and $5 \mathrm{~mm}$ thick of Ti with 5 and $10 \%$ (in volume) of either micrometric or nanometric HA were fabricated. These samples were polished mechanically using Si carbide sandpaper from grade 100, 240, 400-600 grits, followed by $1 \mu \mathrm{m}$ diamond finish, for microstructural analyses. The powders and the sintered materials were analyzed by scanning electron microscopy (SEM), transmission electron microscopy (TEM), X-ray diffraction (XRD), differential scanning calorimetry (DSC) and thermal gravimetric analysis (TG). The SEM analyses were carried out under a Zeiss DSM 940A microscope (Germany) operating at $20 \mathrm{kV}$ and under a JEOL JSM-6360LV microscope (Japan) operating at $15 \mathrm{kV}$. The TEM images, performed in a JEOL 2000FX microscope (Japan) operating at $200 \mathrm{kV}$, were used to analyze the nanometric powder. A Shimadzu XRD-6000 X-ray diffractometer (Japan) was used to identify the phases. A CuK radiation source was used and the incidence beam scan was $2^{\circ} / \mathrm{min}$. The diffraction angle range was between $15^{\circ}$ and $80^{\circ}$, with incremental steps of $0.02^{\circ}$ and a count time of 0.6 seconds. Calorimetry and thermogravimetry analyses were performed in a Netzsch equipment (Jupiter STA 449C). These analyses were carried out in argon atmosphere from room temperature up to $1300{ }^{\circ} \mathrm{C}$ at a heating speed of $5{ }^{\circ} \mathrm{C} / \mathrm{min}$ on the powders containing 5 and $10 \%$ in volume of HA.

\subsection{Compression test}

Samples of Ti with 5, 7.5 and $10 \%$ in volume of HA were produced and tested by compression at $0.5 \mathrm{~mm} / \mathrm{min}$ using an EMIC DL30000 machine interfaced to a computer. Samples tested were 5 cylinders of $10 \mathrm{~mm}$ in diameter and $12 \mathrm{~mm}$ high for each composition.

\subsection{In vitro test}

The capability to induce Ca-P precipitation on the sample surfaces were analyzed by SEM on composites containing $10 \%$ in volume of HA after immersion in a simplified simulated body fluid solution (S-SBF). After sintering the samples were soaked in $16 \mathrm{~mL}$ of S-SBF solution at $37{ }^{\circ} \mathrm{C}$ for 3 days, removed from the S-SBF solution, washed with distilled water and dried in air atmosphere.
The simplified solution (S-SBF), which was designed by Resende et al. ${ }^{20}$ in their quest for a less complex composition, consists of sodium bicarbonate ( $99.7 \%$ pure), dipotassium hydrogen phosphate (99\% pure) and calcium chloride (96\% pure). All reagents were from VETEC Química Fina, Brazil. The impurities present in the precursor reagents were specified by the company. The preparation consists of sequentially dissolving reagent-grade $\mathrm{NaHCO}_{3}, \mathrm{~K}_{2} \mathrm{HPO}_{4} \cdot 3 \mathrm{H}_{2} \mathrm{O}$ and $\mathrm{CaCl}_{2}$ in distilled water at approximately $36.5^{\circ} \mathrm{C}$ buffered to $\mathrm{pH}=7.4$ with Tris-hydroxymethyl aminomethane (TRIS) and $\mathrm{HCl}$, according to the guidelines set forth in the ISO 23317:2007 standard.

\section{Results and Discussions}

\subsection{Morphology of the raw materials}

It can be seen from Figure 1 that the morphologies of both $\mathrm{Ti}$ and HA powders are different. The former had an irregular particle shape (Figure 1a), while the latter had agglomerates of spherical or quasi-spherical particles (Figure 1b-e), which was attributed to the different fabrication methods. Contrary to the HA, the Ti powder had a great variation in particle size. The mean particle size was of approximately $80 \mu \mathrm{m}$ for Ti powder and $1 \mu \mathrm{m}$ and $80 \mathrm{~nm}$ for micrometric and nanometric HA, respectively. Figure 2 shows the XRD spectrum of $\alpha$-Ti (JCPDS 44-1294 card) and hydroxyapatite (JCPDS 72-1243) powders. The nanometric and micrometric HA powders exhibit a similar spectra. All the peaks of Figure $2 \mathrm{~b}$ were identified as HA.

In order to ensure a uniform mixing the mixtures were ground up to 5 hours. Figure 3 is a representative image of the morphology obtained after 5 hours of milling of Ti with $10 \%$ of either micrometric (Figure $3 \mathrm{a}$ ) or nanometric (Figure 3b) HA powders. It can be seen that the agglomerates of the starting materials were broken down and reduced to smaller particulates. In both cases, the presence of small agglomerates of HA on titanium particles can also be observed. Fine particles can be seen attached to the surface of titanium while agglomerates lie in the form of layers. In general, the mixture with nanometric HA presents fewer agglomerates and a more even distribution of calcium phosphate. One possible explanation is that the thermal treatment at $1100{ }^{\circ} \mathrm{C}$ leads to a sintering process of HA powder, bonding strongly the particles in the agglomerates, making it more difficult to break down the agglomerates of micrometric HA. As a result of this sintering process, the nanometric HA presented thinner particulates than that of micrometric HA in the mixtures after 5 hours of milling. Agglomerate size may also play a role in the dispersion and size of HA particulates during milling, since micrometric HA displays larger agglomerates when compared to nanometric HA. Due to its ductile nature, titanium particles presented plastic deformation but not any relevant grain size change during the milling.

\subsection{Microstructure and phase composition of the composites}

XRD patterns of the sintered composites displayed peaks of $\alpha$-titanium, calcium titanate (JCPDS 22-0153 card), rutile (JCPDS 21-1276 card), tricalcium phosphate (JCPDS 09-0169 card) and $\mathrm{Ti}_{\mathrm{x}} \mathrm{P}_{\mathrm{y}}$ phases (Figure 4). The XRD pattern of pure Ti powder was also included in Figure 4 for comparison purposes. It can be seen that there is no shift in the Ti peaks of the composites, compared to pure Ti, indicating that there is no solid solution and/or a significant amount of impurities in titanium structure. It is more likely that the phosphor forms $\mathrm{Ti}_{\mathrm{x}} \mathrm{P}_{\mathrm{y}}$-like compounds instead of a solid solution with Ti. The $\mathrm{Ti}_{\mathrm{x}} \mathrm{P}_{y}$ peaks identified by XRD may be from $\mathrm{Ti}_{5} \mathrm{P}_{3}$ (45-0888) and/or $\mathrm{Ti}_{4} \mathrm{P}_{3}$ (22-0944). As the main peak of rutile is at approximately $2 \theta=27$ degree in its diffraction pattern, this phase is probably not 


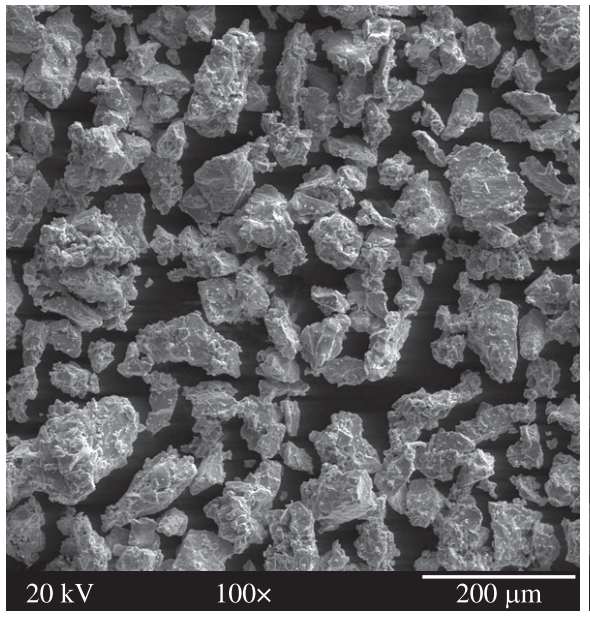

(a)

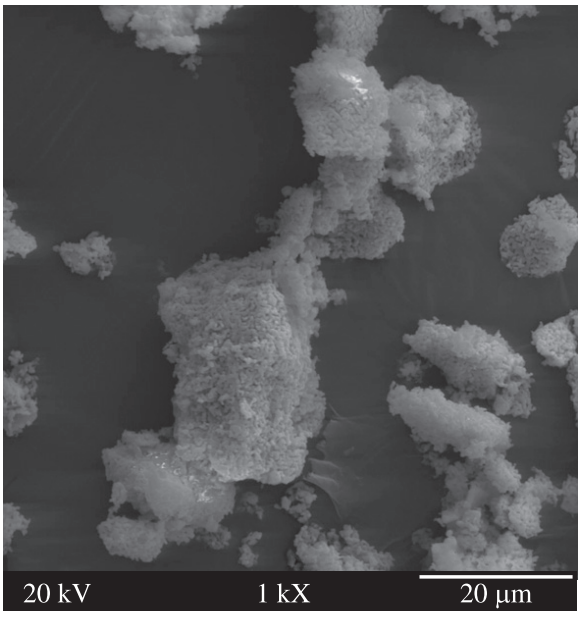

(b)

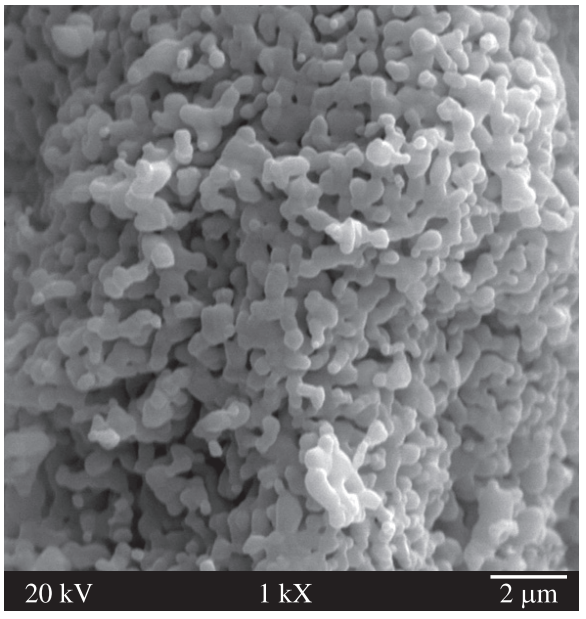

(c)

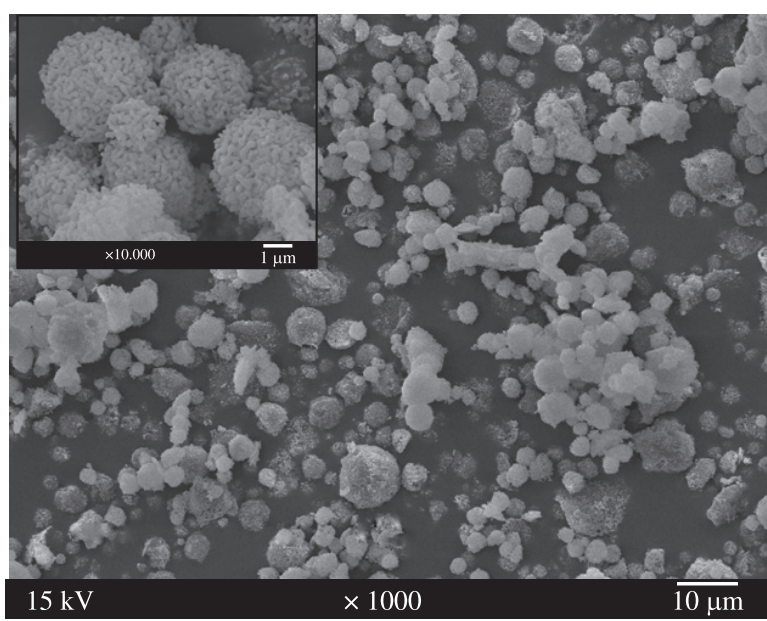

(d)

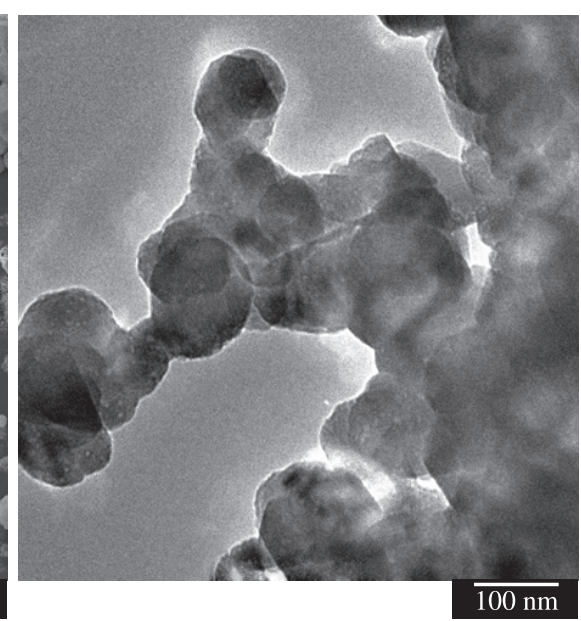

(e)

Figure 1. Morphology of the starting powders. a) SEM images of pure Ti; b, c) SEM images of micrometric HA; and d) SEM; and e) TEM images of nanometric HA.

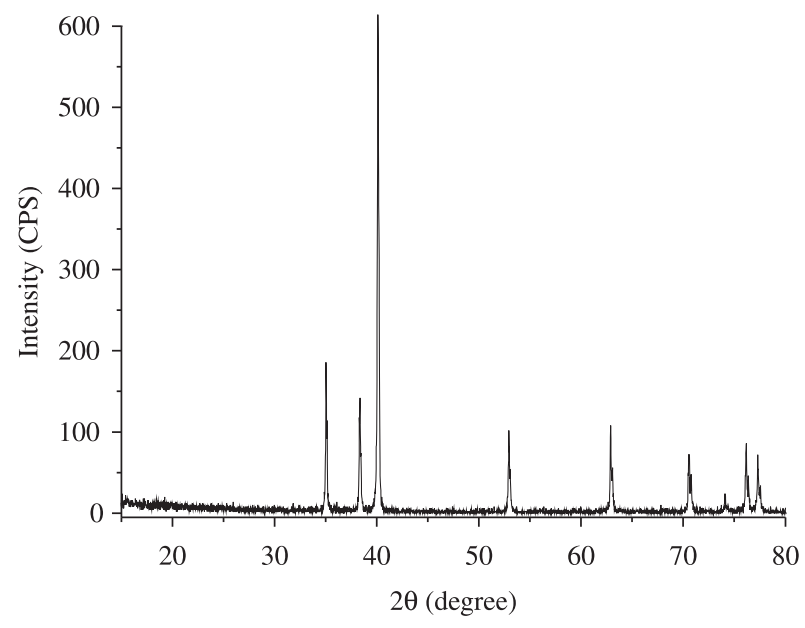

(a)

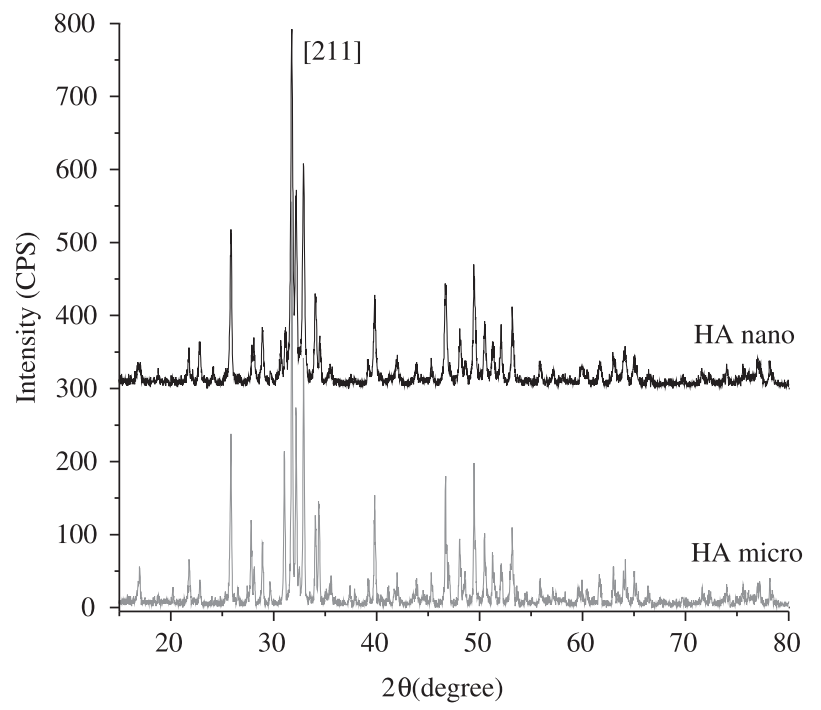

(b)

Figure 2. XRD patterns of the raw materials: a) pure $\alpha$-Ti; and b) hydroxyapatite powders. 


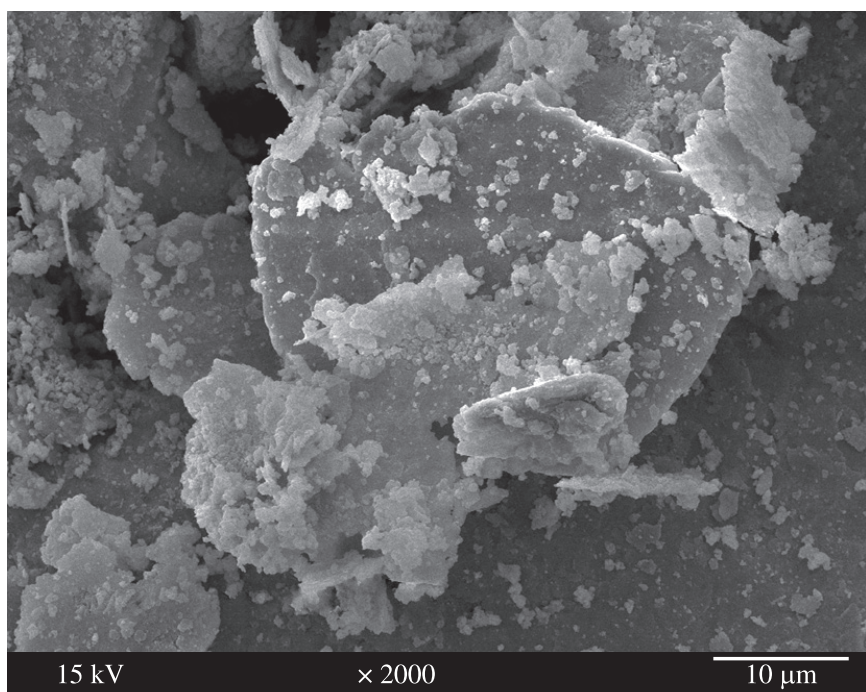

(a)

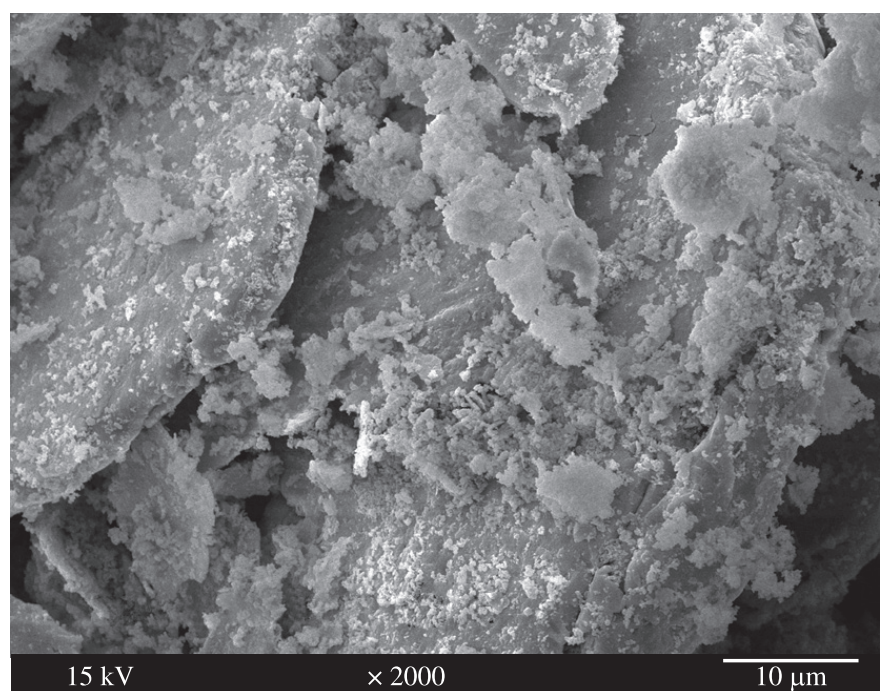

(b)

Figure 3. SEM images showing HA particulates dispersed in pure Ti-based powder after 5 hours of milling. a) Ti with $10 \%$ of micrometric HA; and b) Ti with $10 \%$ of nanometric HA.

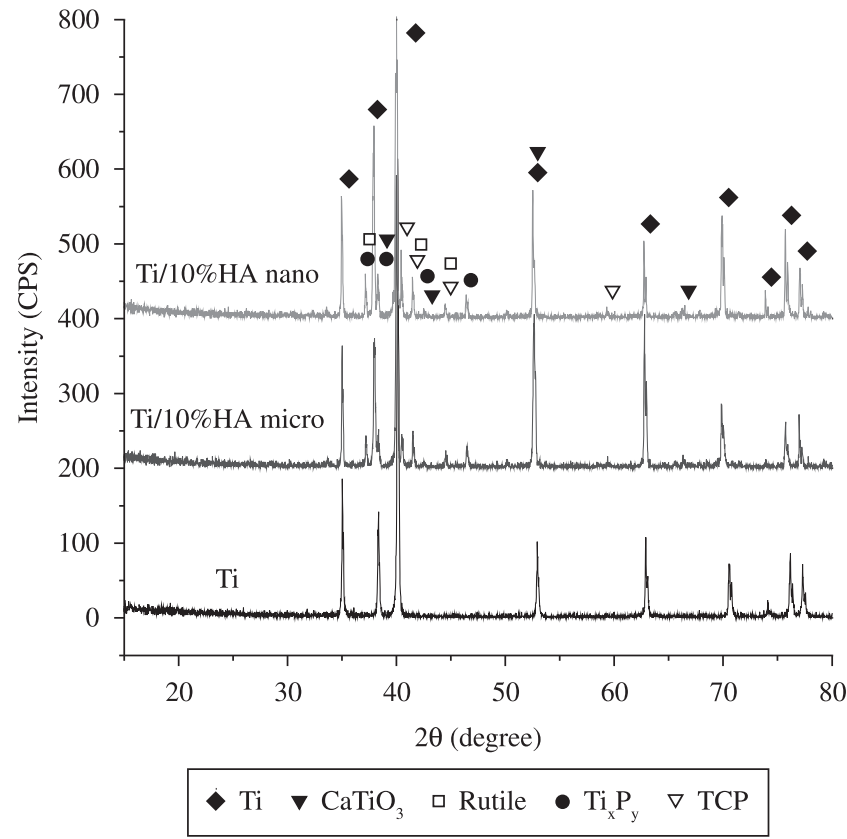

Figure 4. XRD patterns of Ti powder and Ti/10\%HA composites sintered at $1200{ }^{\circ} \mathrm{C}$ for 2 hours.

present in the composites, at least in significant amount. However, it is worth recalling that Ti particles of the starting material are covered with a passive oxide film of anatase. During the heating, the anatase is converted into crystalline rutile $\left(>730{ }^{\circ} \mathrm{C}\right)^{21}$. Furthermore, since oxygen is trapped inside the pores of the green compact during mechanical densification, more rutile can be form during the heating.

Images from the polished surfaces revealed that composites with 5\% HA were reasonably well sintered (Figures 5a e 6a). However, the micrometric HA composite showed, in general, more porosity than the nanometric HA composite. Also, the composites with $10 \% \mathrm{HA}$ are not well sintered, as can be seen in Figures $5 \mathrm{~b}$ and $6 \mathrm{~b}$, which is mainly the case with the micrometric HA composite. It can also be noted that polished surfaces are not even, in particular in the composite with $10 \%$ of micrometric HA, thus indicating that parts of the material are scraped off during polishing of the samples. Chemical analyses (EDS) and metallographic analyses showed that the phases formed between titanium particles are partially removed during polishing. Figures $5 c$ and $6 c$ display only the presence of phosphor on the surface of titanium particles. No significant concentration of calcium was found on the polished surfaces. These analyses demonstrate that phases containing calcium, which are formed between titanium particles, are fragile and consequently removed during polishing. This is why polished surfaces display an uneven appearance, with gaps and pores between titanium particles.

The uneven characteristic of polished surfaces can be seen more clearly with enlarged images. Figure 7 a shows the polished part and the interface part with the intergranular region of a titanium particle. Figure $7 \mathrm{~b}$ shows line scan analysis by EDS of Ti, $\mathrm{Ca}, \mathrm{P}$ and $\mathrm{O}$ carried out in the position and direction of the arrow indicated in Figure $7 \mathrm{a}$. Vertical arrows in Figures 7a, b indicate the position from which phosphor was detected. In the polished part, only Ti was detected. In the interface area, Ti and $\mathrm{P}$ were detected. These analyses indicate that phosphor diffusion into titanium particles took place during sintering process, thus forming $\mathrm{Ti}_{\mathrm{x}} \mathrm{P}_{\mathrm{y}}$ type phases, as demonstrated by $\mathrm{X}$-ray diffraction analyses. These analyses also confirm that phases containing calcium came off during polishing of samples.

Some samples were fractured by compression to analyze the microstructure of the intergranular material. Figures 8 and 10 show the phases formed by reaction between titanium and HA during the sintering. It can be seem that titanium particles are covered with a compact layer and a brighter porous material. The porous material has a typical structure of treated HA and/or tricalcium phosphate powders ${ }^{22,23}$. The chemical composition of this material confirms that it is a calcium phosphate phase (Figure 9), which was identified as tricalcium phosphate $\left(\mathrm{Ca}_{3}\left(\mathrm{PO}_{4}\right)_{2}\right)$ by XRD (Figure 4 ).

EDS analysis (Figure 11) showed that the compact layer indicated by the letter A in Figure 10 corresponds to the calcium titanate phase formed between titanium particles during sintering. Phosphor found in Figure 11 is likely to be from the $\mathrm{Ti}_{\mathrm{x}} \mathrm{P}_{\mathrm{y}}$ phase.

Figure 12 shows the thermal analysis of Ti-based composites. Up to $730^{\circ} \mathrm{C}$ the peaks observed are essentially from titanium oxidation due to the residual air trapped inside the camera. This oxidation is 


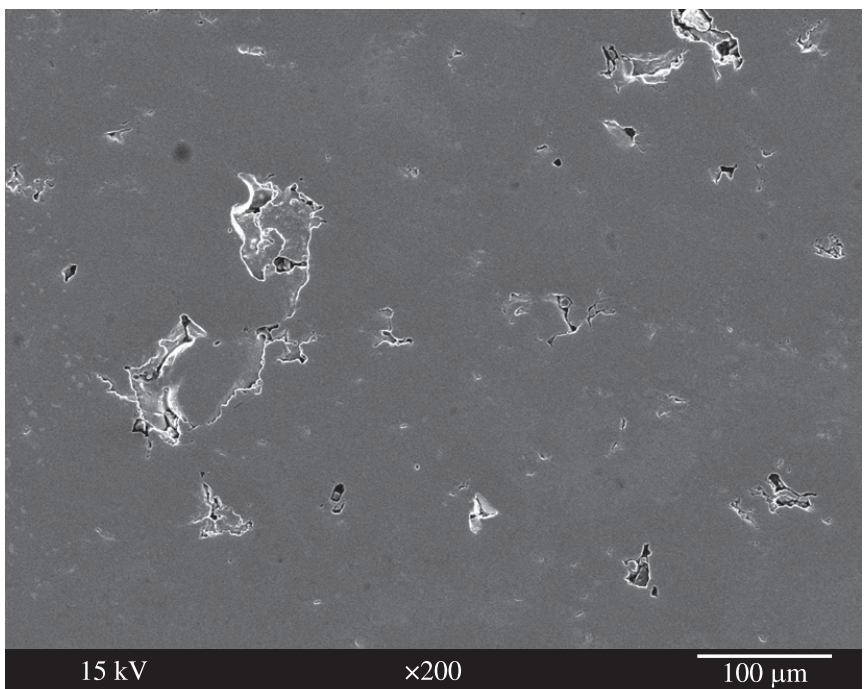

(a)
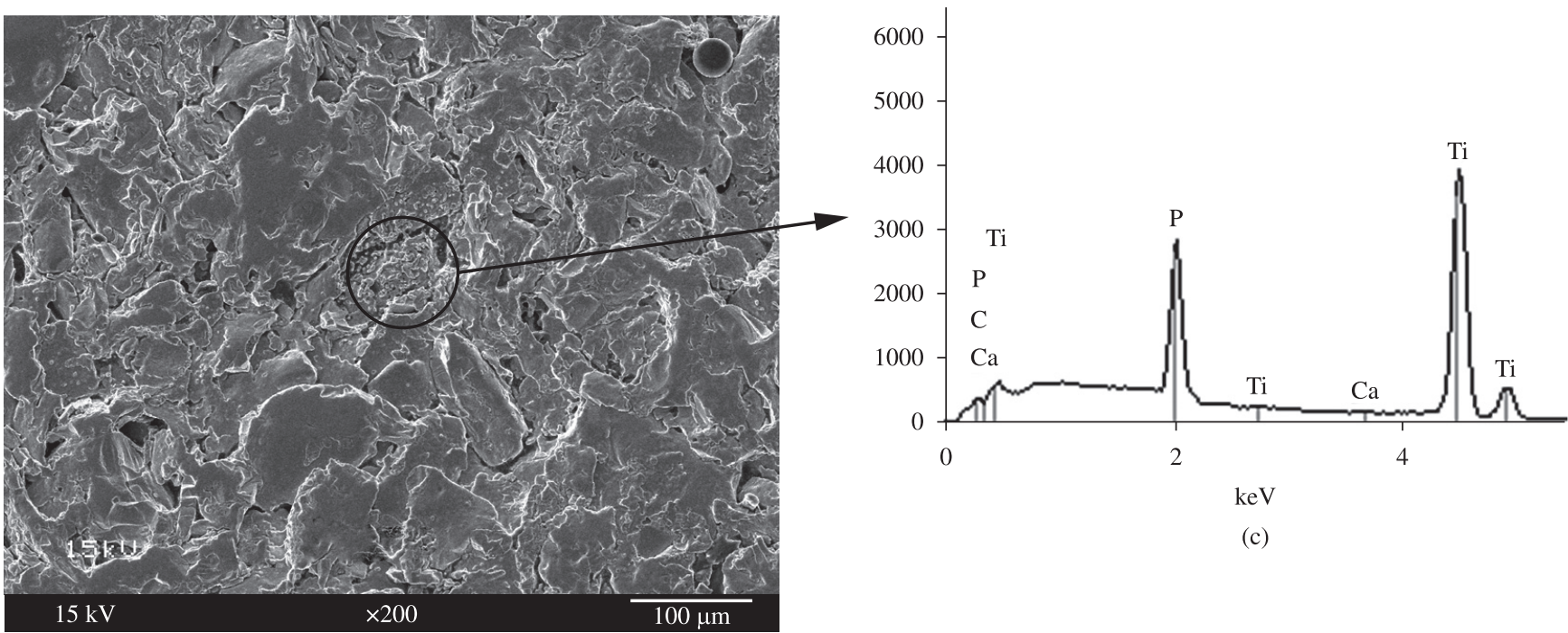

(c)

(b)

Figure 5. SEM micrographs of polished surfaces showing the morphology of Ti/HA composites produced with a) $5 \%$; and b) $10 \%$ in volume of micrometric HA. c) EDS analysis of a region containing P.

responsible for the weight gain recorded during the tests. As the equipment is unable to perform a vacuum, the air was swapped by an argon flow of high purity before the tests. It is unlikely that this procedure was sufficient to achieve a complete elimination of the air. The peak at about $50{ }^{\circ} \mathrm{C}$ is due to volatilization of alcohol molecules adsorbed on the surface of the passive film. At approximately $460{ }^{\circ} \mathrm{C}$ rutile begins to nucleate and then the oxide film is constituted of anatase and rutile sublayers ${ }^{21}$. The peak at $725-730{ }^{\circ} \mathrm{C}$ indicates that anatase is no longer stable, converting to rutile, which is the only stable oxide above $730^{\circ} \mathrm{C}^{21}$. The exothermic reaction at approximately $1023-1026{ }^{\circ} \mathrm{C}$ is related to the decomposition of HA. A theoretical study has demonstrated that calcium titanate is thermodynamically stable above $1000^{\circ} \mathrm{C}^{10}$. A barely discernable peak at $1260^{\circ} \mathrm{C}$ was also detected by DSC (Figure 12). The analyses were repeated many times and this peak appeared in some analyses and more often in Ti with micrometric HA. This peak was attributed to $\alpha$-tricalcium phosphate $(\alpha-$ TCP). In the analyses little amount of material was used (about $20 \mathrm{mg}$ ) and as the mixtures contain agglomerates of HA, the samples may contain more or less agglomerates. This might be the reason why the peak at $1260{ }^{\circ} \mathrm{C}$ was not always detected by DSC analyses.

It is well known that over $1100{ }^{\circ} \mathrm{C}$ the $\mathrm{HA}$ is transformed into $\beta$-TCP, which is converted in $\alpha$-TCP at approximately $1200{ }^{\circ} \mathrm{C}^{24}$. This indicates that HA can be transformed into calcium titanate and $\beta$-TCP at $1023-1026^{\circ} \mathrm{C}$. According to MEV analyses of the mixtures and phase distributions, the green compacts contain agglomerates (thick layers) of HA between titanium particles. Therefore, the TCP phase found in the analyses is more likely related to the amount of HA trapped between Ti particles during the fabrication process. The sintering conditions (time and temperature) were not sufficient to convert all the $\beta$-TCP from the agglomerates into calcium titanate and $\mathrm{Ti}_{x} \mathrm{P}_{y}$ phases, contrary to the thin layers/amount of HA trapped between Ti particles. After 2 hours at $1200{ }^{\circ} \mathrm{C}$ the $\beta$-TCP that was not consumed was converted in $\alpha$-TCP. During the cooling $\alpha$-TCP tends to be transformed in $\beta$-TCP. Therefore, most of this compound identified by XRD is in the form of $\beta-\mathrm{Ca}_{3}\left(\mathrm{PO}_{4}\right)_{2}$, but some amount of $\alpha-\mathrm{Ca}_{3}\left(\mathrm{PO}_{4}\right)_{2}$ is also likely to be present. 


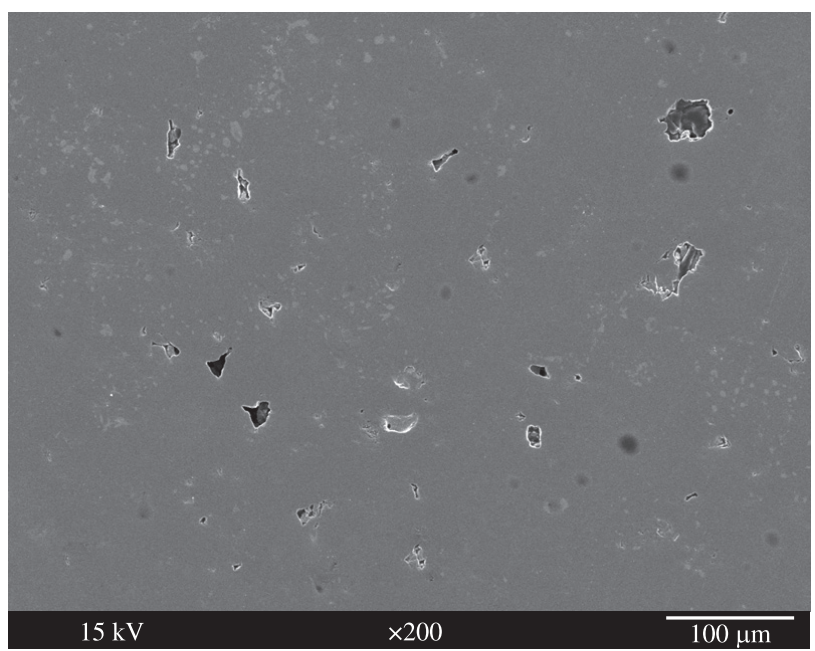

(a)
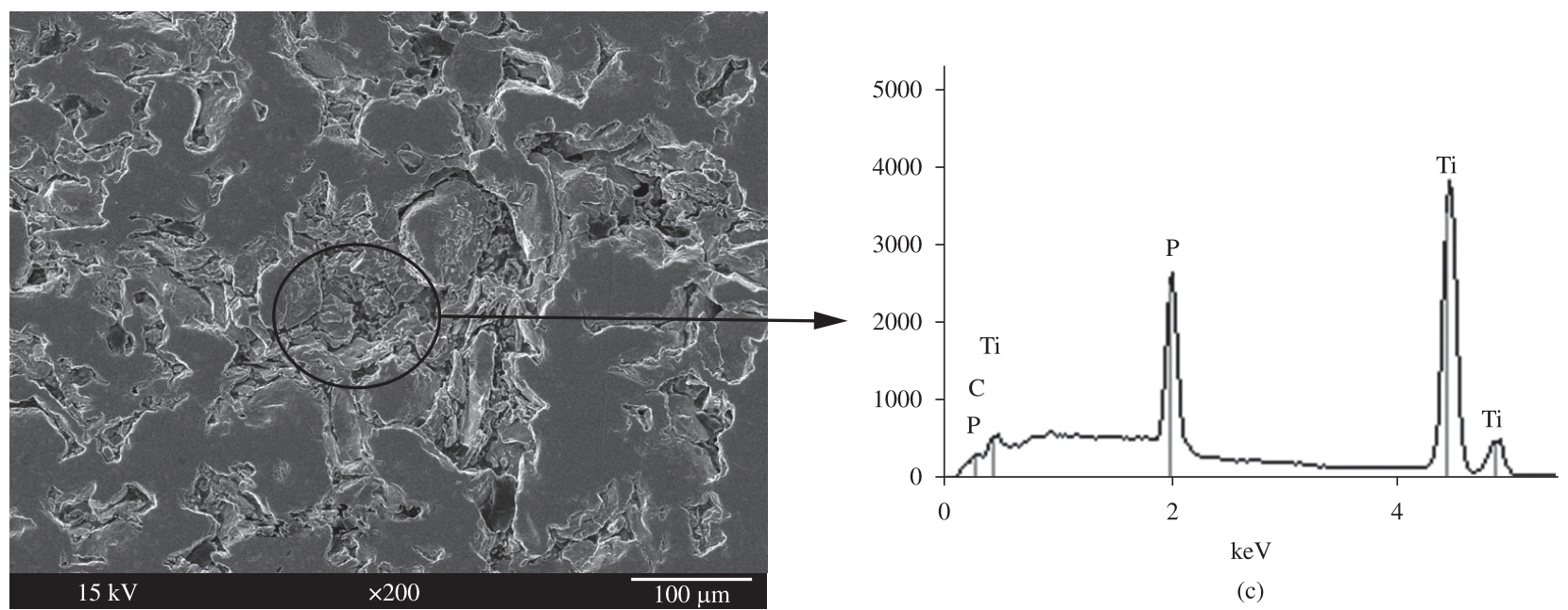

(c)

(b)

Figure 6. SEM micrographs of polished surfaces showing the morphology of Ti/HA composites produced with a) $5 \%$; and b) $10 \%$ in volume of nanometric HA. c) EDS analysis of a region containing P.

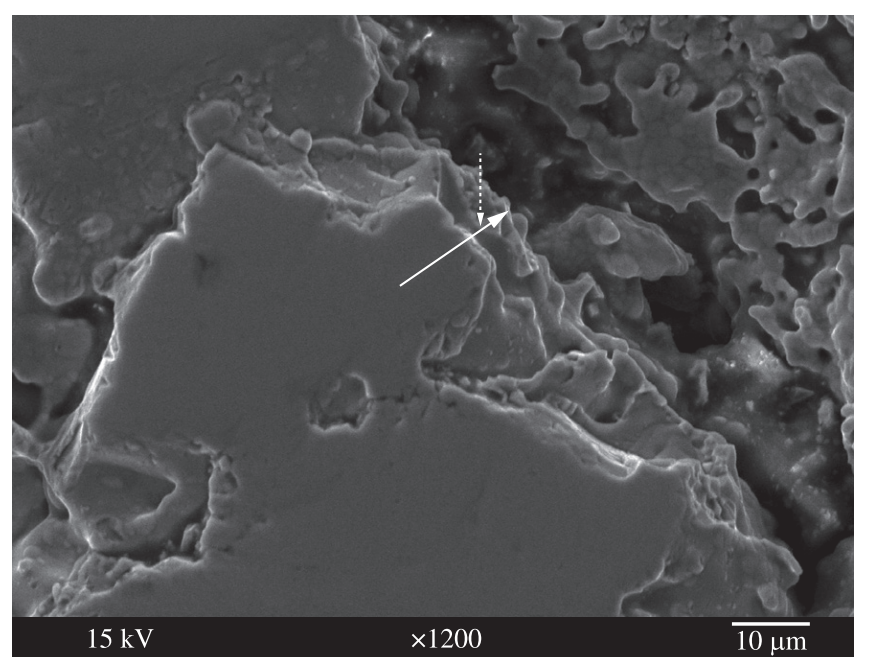

(a)

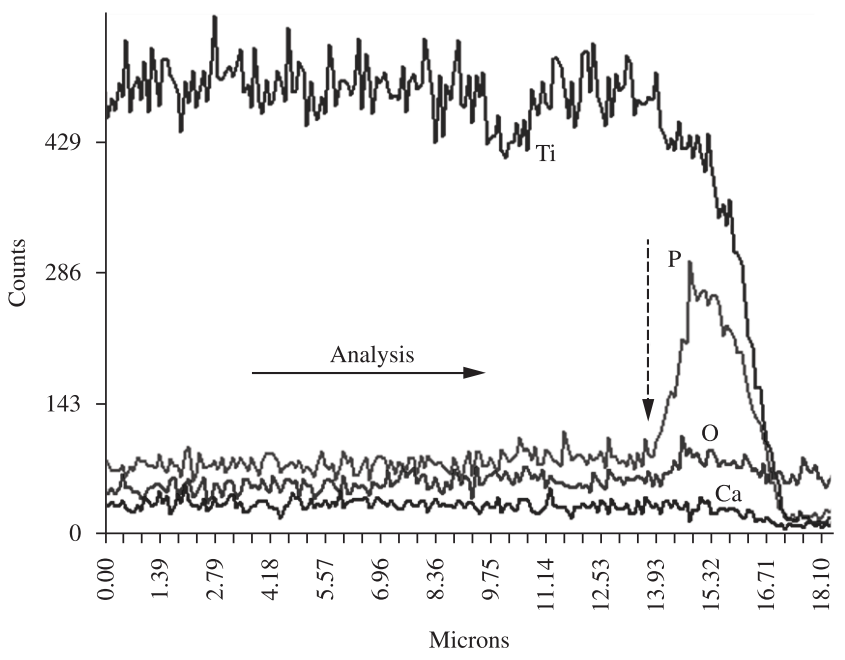

(b)

Figure 7. Analysis carried out by SEM on the polished surface of a sintered sample of nanometric Ti/10\% HA. a) Image from the polished surface; and b) EDS line scan analyses of Ti, Ca, P and $\mathrm{O}$ carried out in the position and direction of the arrow in Figure 7a. Vertical arrows indicate the position from which phosphor was detected. 


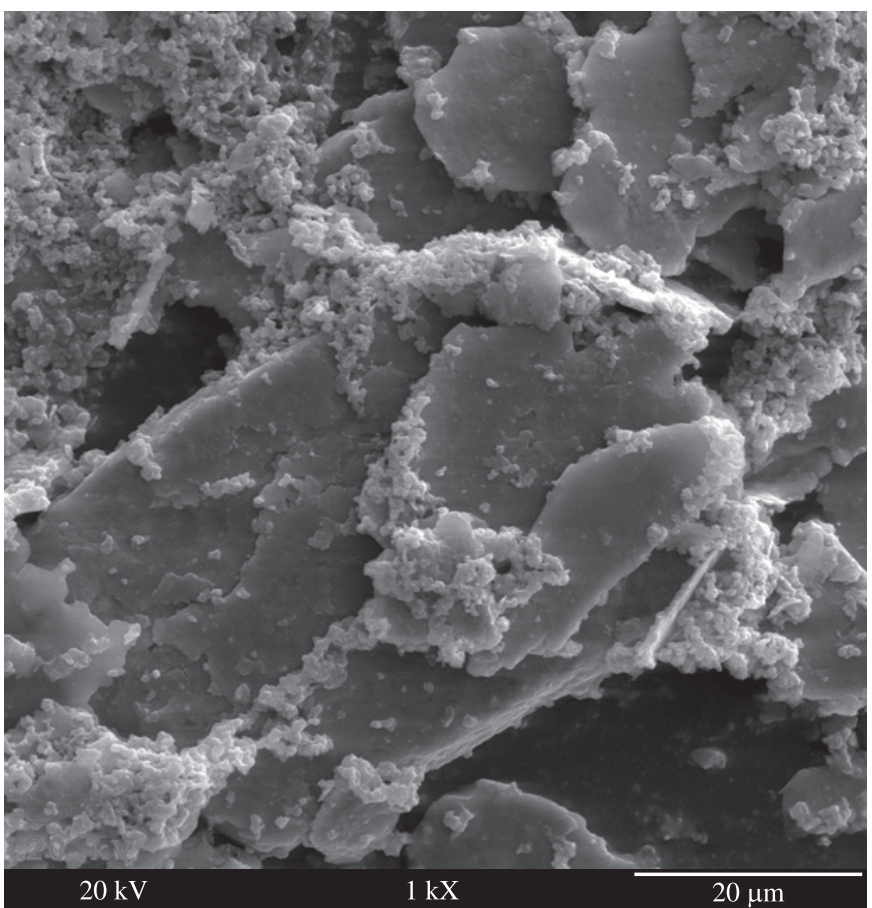

(a)

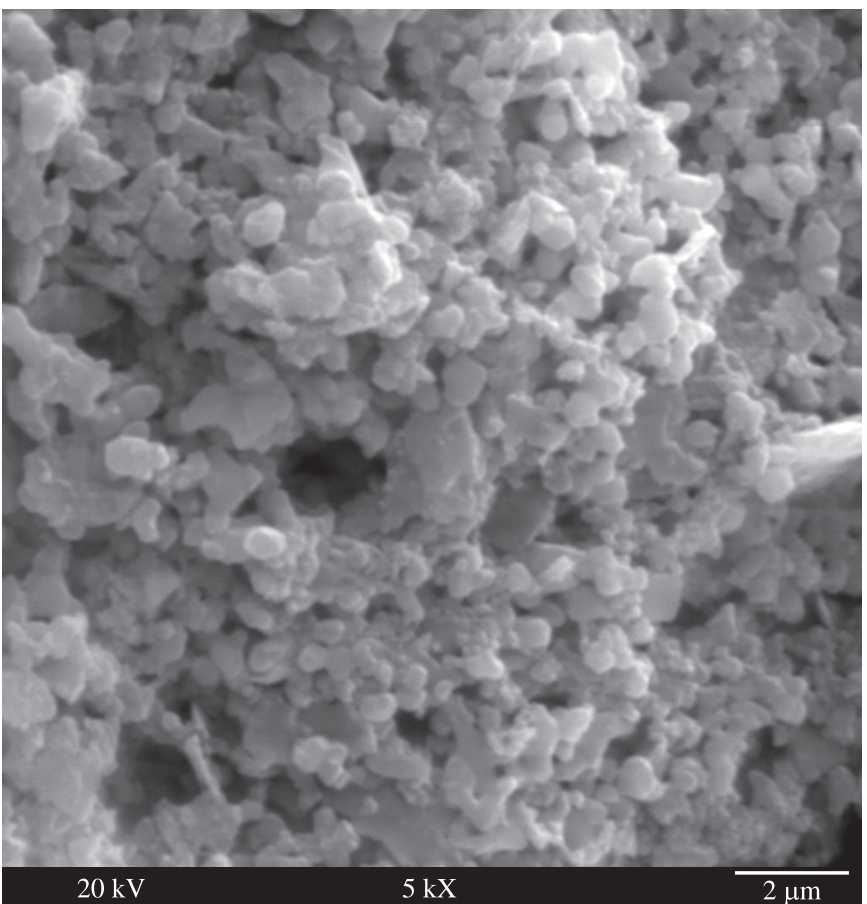

(b)

Figure 8. SEM micrographs of the fracture surfaces of Ti-based composite produced with $10 \%$ in volume of micrometric HA. a) General view; and b) TCP structure in Ti intergranular material.

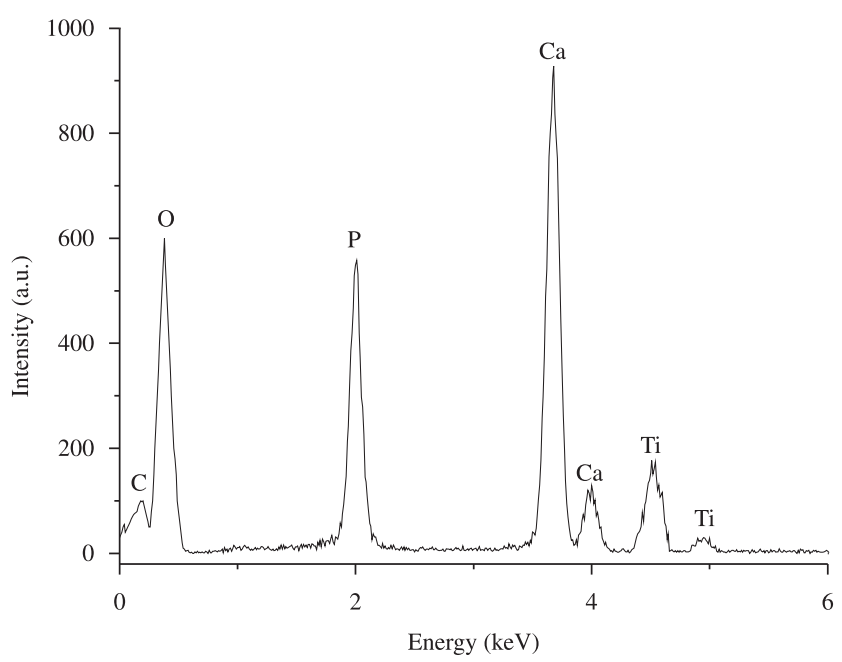

Figure 9. EDS analysis of the porous material (TCP) found between Ti particles in the Ti-based composite produced with $10 \%$ in volume of micrometric HA.

It should now be clear from TEM, XRD and DSC analysis that the sintering process leads to the formation of calcium titanate $\left(\mathrm{CaTiO}_{3}\right)$, $\mathrm{Ti}_{\mathrm{x}} \mathrm{P}_{\mathrm{y}}$ phase(s) and tricalcium phosphate. The latter being found in some parts in Ti particle boundaries. The sequence in which the above events have occurred, and the series of possible sintering reactions can be expressed in two steps. The first one involves the reaction of rutile film formed on titanium particles and $\mathrm{HA}^{10}$ :

$$
\mathrm{Ca}_{10}\left(\mathrm{PO}_{4}\right)_{6}(\mathrm{OH})_{2}+\mathrm{TiO}_{2} \rightarrow 3 \mathrm{Ca}_{3}\left(\mathrm{PO}_{4}\right)_{2}+\mathrm{CaTiO}_{3}+\mathrm{H}_{2}+1 / 2 \mathrm{O}_{2}
$$

This reaction leads to the formation of calcium titanate, $\beta$-tricalcium phosphate and gas; the latter being released into the pores and/or to the composite surface. At approximately the same temperature, the hydroxyapatite not involved in the reaction with rutile decomposes in TCP and water vapor. Step two takes place when all rutile is consumed. As titanium is covered with a calcium titanate film (Figure 13a), the growth of this phase as well as the formation of $\mathrm{Ti}_{\mathrm{x}} \mathrm{P}_{\mathrm{y}}$ phase(s) can only take place by solid state diffusion of titanium and phosphor through the titanate film (Figure 13b). Titanium diffuses through the film to react with tricalcium phosphate and the oxygen contained in the pores, forming calcium titanate. This reaction release $\mathrm{P}$, which tends to diffuse to the interface II to form $\mathrm{Ti}_{\mathrm{x}} \mathrm{P}_{\mathrm{y}}$ phase(s). These reactions may proceed until complete consumption of TCP as it occurs in the thinner layer/amount of HA, between titanium particles. In the thicker layer/areas the reaction is not completed and the remaining TCP is transformed in $\alpha$-TCP.

The formation of $\mathrm{Ti}_{\mathrm{x}} \mathrm{P}_{\mathrm{y}}$ phase(s) was also pointed out in composites produced with Ti and HA powders ${ }^{10-14}$. Some researchers report the presence of phases like $\mathrm{Ti}_{4} \mathrm{P}_{3}$ or $\mathrm{Ti}_{5} \mathrm{P}_{3}{ }_{3}^{12}$, or $\mathrm{Ti}_{3} \mathrm{P}_{4}{ }^{10}$ without any convincing analyses. Ning and $\mathrm{Zhou}^{13}$ have examined by TEM the microstructure of this $\mathrm{Ti}_{x} \mathrm{P}_{y}$ phase(s) in biocomposites sintered from Ti, HA and bioactive glass. They noted that in the composites sintered at $1200{ }^{\circ} \mathrm{C}$ the $\mathrm{Ti}_{\mathrm{x}} \mathrm{P}_{\mathrm{y}}$ grains were always interfaced by $\mathrm{CaTiO}_{3}$ ones as observed here. TEM-EDS analyses revealed that the $\mathrm{x} / \mathrm{y}$ ratio for $\mathrm{Ti}_{\mathrm{x}} \mathrm{P}_{\mathrm{y}}$ compounds had mainly two values, 0.96 and 1.66 . The amount of the former was much larger than that of the latter. Although these two $\mathrm{Ti}_{\mathrm{x}} \mathrm{P}_{\mathrm{y}}$ compounds showed similar chemical compositions to those of TiP and $\mathrm{Ti}_{17} \mathrm{P}_{10}$, their electron diffraction and XRD patterns did not agree with those of $\mathrm{TiP}$ and $\mathrm{Ti}_{17} \mathrm{P}_{10}$.

\subsection{Compression test}

The mechanical behavior of the composites was studied by compression tests. Figure 14 shows the compression strength of these materials. All the biocomposites presented a fragile behavior without displaying any yield stress before the rupture, contrary to pure sintered 


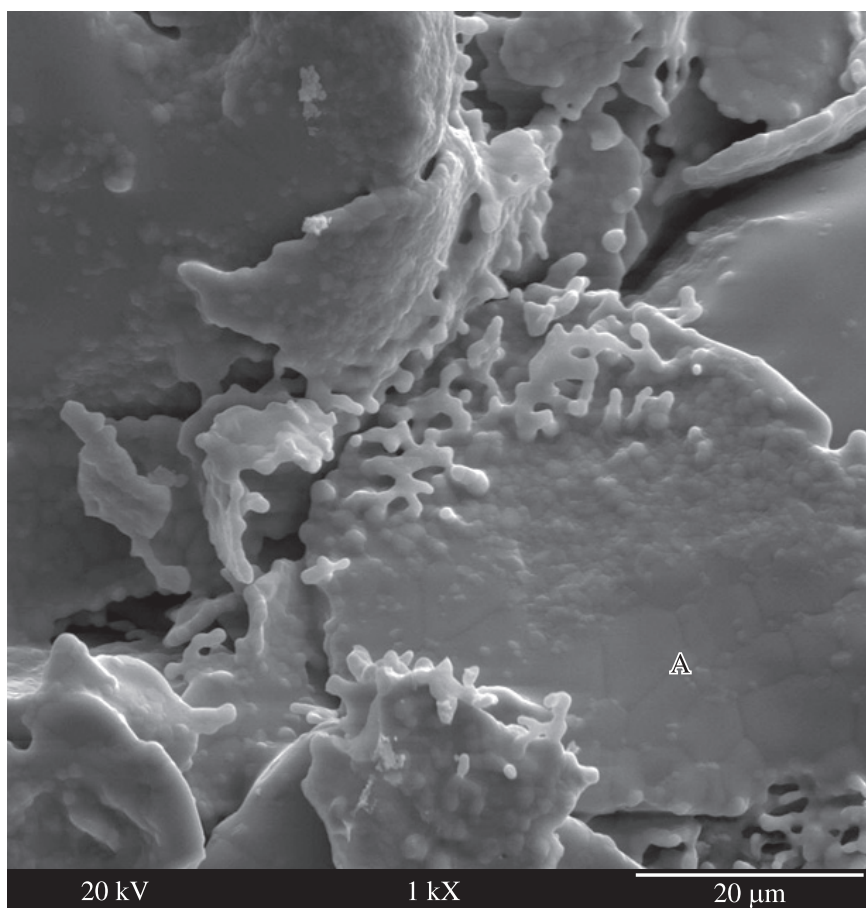

(a)

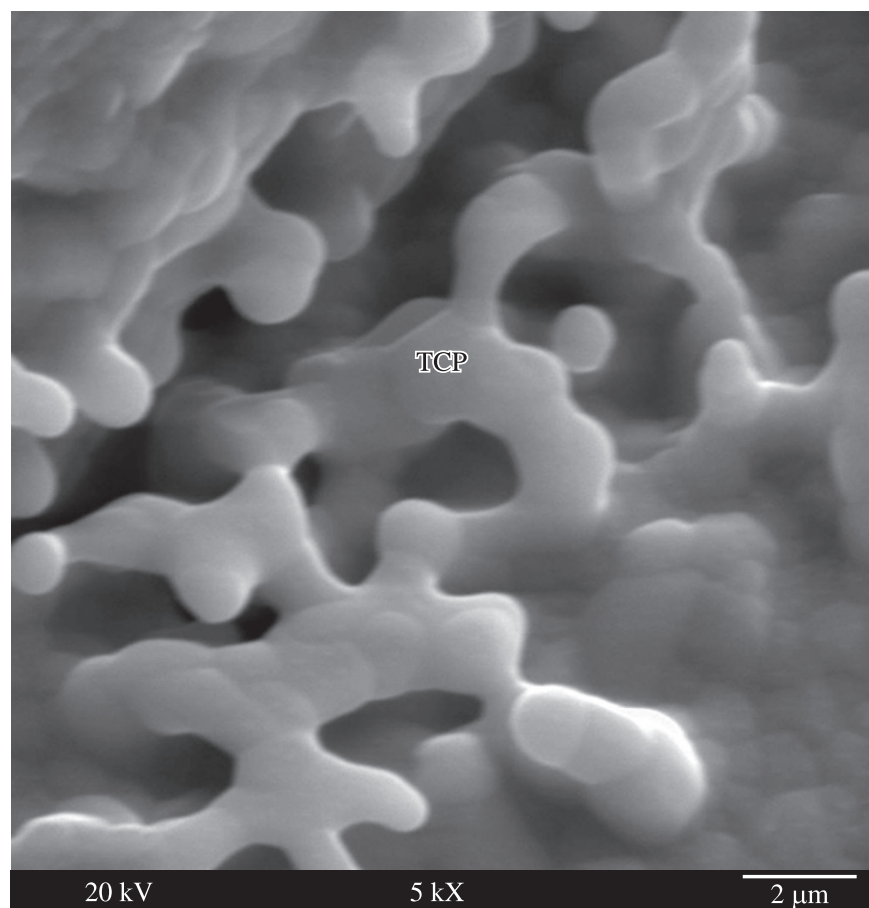

(b)

Figure 10. SEM micrographs of the fracture surfaces of Ti-based composite produced with $10 \%$ in volume of nanometric HA. a) General view; and b) TCP structure in Ti intergranular material.

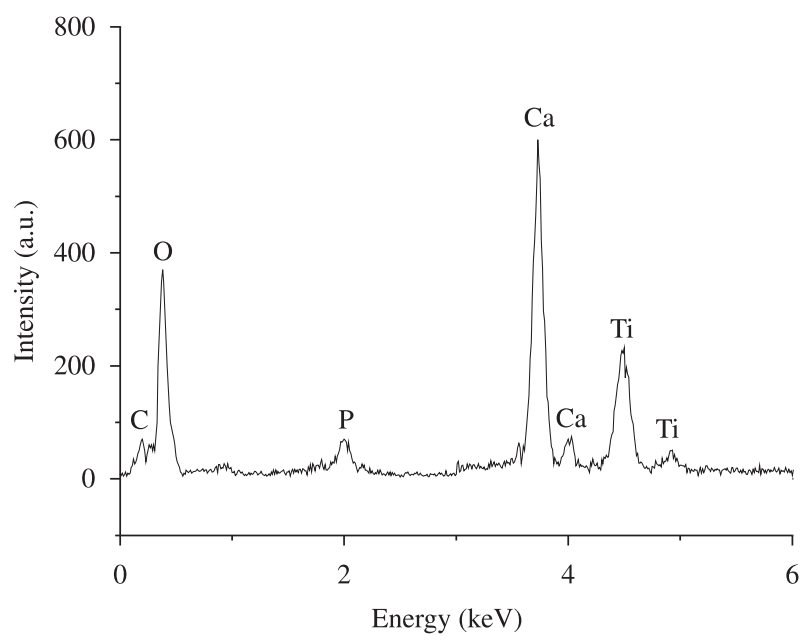

Figure 11. EDS analysis in point A of Figure 10a of the compact layer formed on Ti particles in the Ti-based composite produced with $10 \%$ in volume of nanometric HA.

titanium, which showed ductile behavior with a yield stress at about $400 \mathrm{MPa}$. It can be observed that the strength declines drastically with the amount of the HA incorporated to the composites, regardless the size particles of the raw materials. However, the compression strength of titanium-based composites produced with nanometric HA is approximately $40 \%$ higher than that produced with micrometric HA.

The compression strength is related to the microstructure and phase distribution in the composites. The phases formed during the sintering are fragile and are located between Ti particles, resulting in an intergranular fracture (Figures 8 and 10).

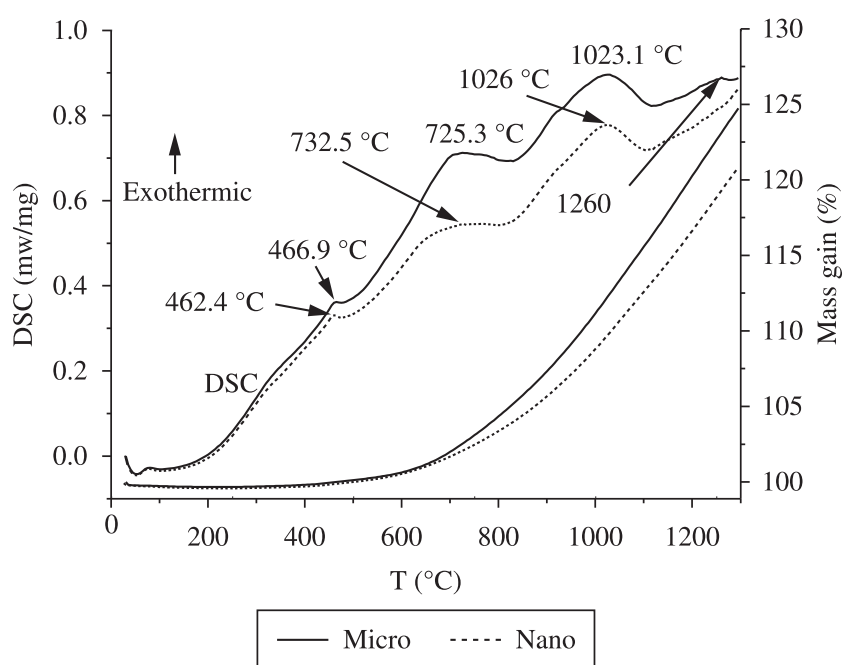

Figure 12. Thermal analysis of Ti-based composite produced with $10 \%$ in volume of either micrometric (micro) or nanometric (nano) HA.

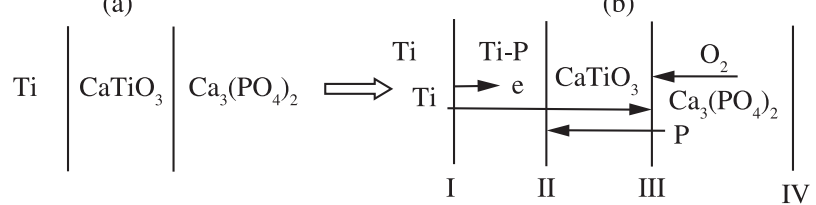

Interface III: $3 \mathrm{Ti}+1 / 2 \mathrm{O}_{2}+\mathrm{Ca}_{3}\left(\mathrm{PO}_{4}\right)_{2}=>3 \mathrm{CaTiO}_{3}+2 \mathrm{P}$ Interface II: $\mathrm{xTi}+\mathrm{yP}=>\mathrm{Ti}-\mathrm{P}\left(\mathrm{Ti}_{\mathrm{x}} \mathrm{P}_{\mathrm{y}}\right)$

Figure 13. Mechanism of nucleation and growth of calcium titanate and $\operatorname{Ti}_{x} \mathrm{P}_{\mathrm{y}}$ phases at $1023-1026^{\circ} \mathrm{C}$. a) decomposition of $\mathrm{HA}$; and b) growth of calcium titanate and $\mathrm{Ti}_{\mathrm{x}} \mathrm{P}_{\mathrm{y}}$ phases in detriment of tricalcium phosphate. 


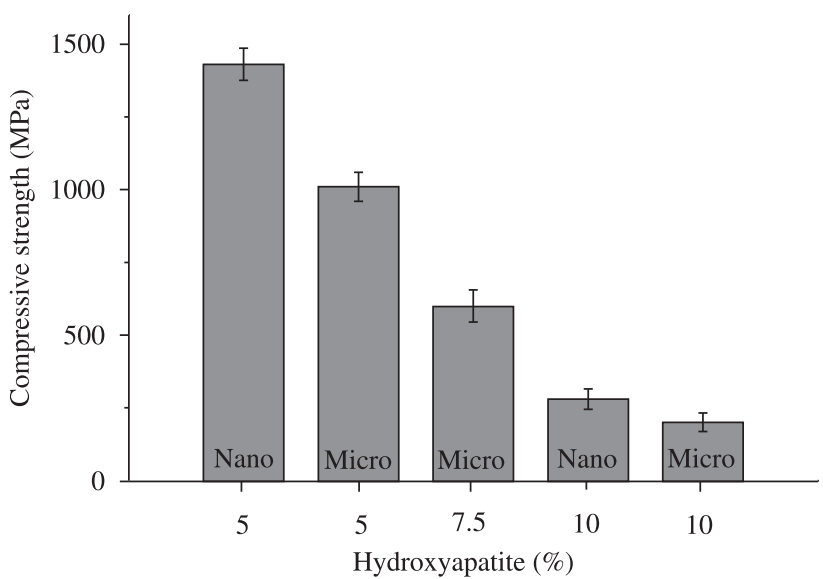

Figure 14. Compression strength of the biocomposites produced with either nanometric (nano) or micrometric (micro) HA.

As mentioned before, the HA is not well dispersed in the composites, especially the micrometric HA. In Figure 8 and 10 it is possible to see that the composites have agglomerates of HA between Ti particles, especially the composites containing micrometric HA. The agglomerates tend to increase with the amount of HA in the composites provoking a significant decrease in the compressive strength of the materials. The nanometric HA is better dispersed in the composites resulting in higher values of compressive strength than the composites produced with micrometric HA.

\subsection{In vitro test}

Figure 15 is a representative image of the composite surfaces after immersion in S-SBF for 3 days. All the specimens displayed a Ca-P layer with plate-like crystals, regardless the HA particle size. The layer was not uniform, especially on the composite produced with micrometric HA. Gaps can be seen in the film due to the heterogeneous nucleation and growth of the Ca-P phases. This heterogeneity may be attributed to the calcium and phosphor phase formation on titanium particles during the sintering. Since the composites displayed HA agglomerates on Ti particles, the bioactive phases formed preferentially on these areas during the sintering, leading to a higher exchange of ions between these areas and S-SBF. As a result, the nucleation and growth of the $\mathrm{Ca}-\mathrm{P}$ phases on these regions prevailed, provoking the formation of gaps in the deposit.

Nucleation and growth of Ca-P phases on bioactive titanium in S-SBF solution was well documented in a recent study ${ }^{25}$. Summarizing, shortly after the immersion in S-SBF solution, precipitation of calcium produces a thin layer of calcium titanate. Then, the process continues with the precipitation of calcium and phosphate on the calcium titanate film, promoting the formation of an amorphous calcium phosphate layer. After 2.5 hours of immersion, the amorphous calcium phosphate layer showed octacalcium phosphate (OCP) nuclei that grew continuously up to 24 hours, forming regular and homogeneous plate-like crystals. Nucleation and growth of OCP occurred along with crystallization of amorphous calcium phosphate into HA. This transformation occurred by solid-state diffusion and took place after approximately 1 hour of immersion, forming islands of HA with a needle-like structure, which grew and crystallized in the transient amorphous calcium phosphate layer. The titanium surface was then essentially covered with an external layer of OCP and an intermediary layer of HA in contact with the OCP layer.

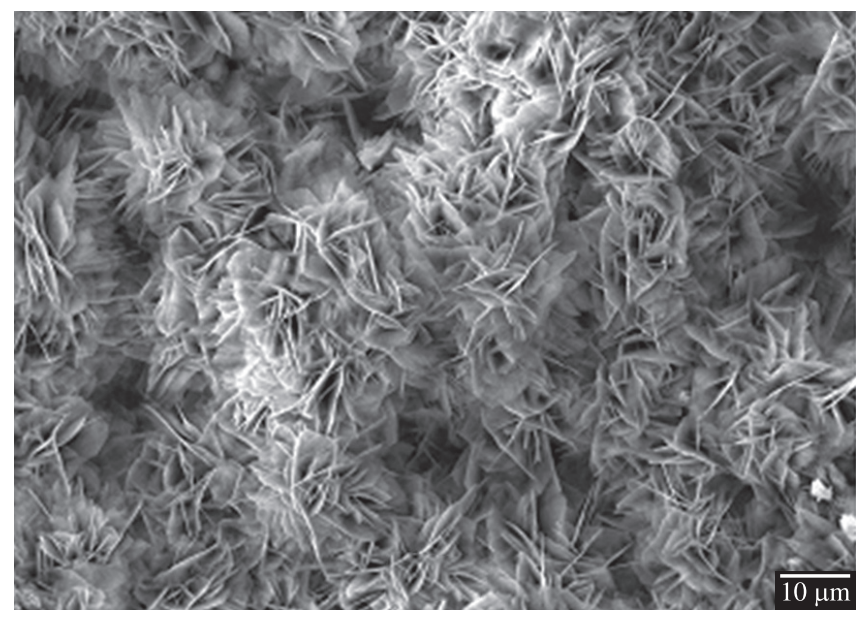

(a)

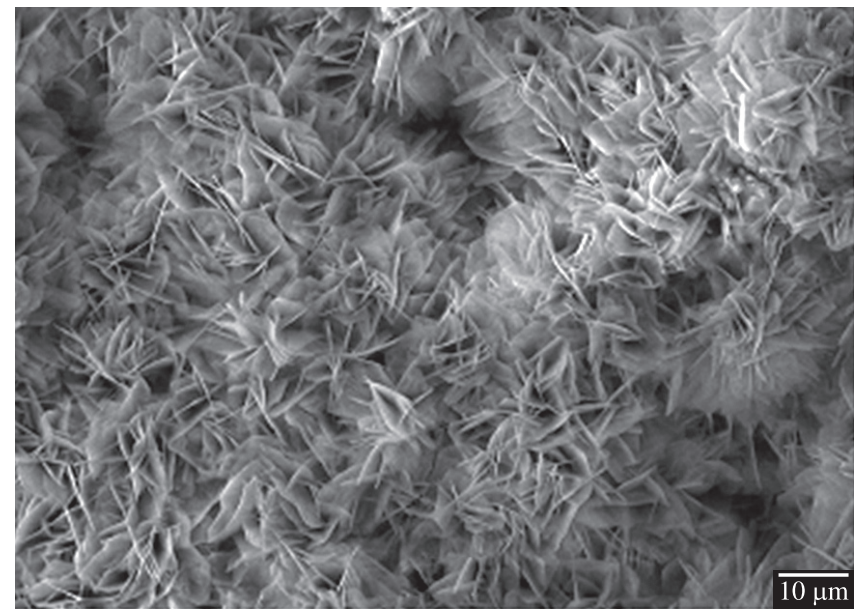

(b)

Figure 15. SEM micrographs of Ti-based composites surfaces after immersion in S-SBF for 3 days. a) Ti with $10 \%$ of micrometric HA; and b) Ti with $10 \%$ of nanometric HA

\section{Conclusion}

This study has shown that nanometric HA composites display better results than micrometric HA composites in terms of microstructure and mechanical strength. Mixtures with nanometric HA presented smaller and better distribution of agglomerates leading to a more uniform Ca-P deposition on the composites in S-SBF. Composites with nanometric HA were better sintered when compared with micrometric HA composites. Decomposition of HA takes place at approximately $1026^{\circ} \mathrm{C}$ leading to the formation of calcium titanate, $\mathrm{Ti}_{\mathrm{x}} \mathrm{P}_{\mathrm{y}}$ and TCP phases. As these phases are formed at Ti particle boundaries, the composites presented an intergranular fracture. The compressive strength decreases with the incorporation of HA. The composites produced with nanometric HA presented higher values of compressive strength than those produced with micrometric HA because the nanometric HA is better dispersed in the composites than the micrometric HA powder.

\section{References}

1. Back HJ and Qasi JI. Titanium alloys for biomedical applications. Materials Science and Enginnering C. 2006; 26:1269-1277. http://dx.doi. org/10.1016/j.msec.2005.08.032 
2. Feng B, Weng J, Yang BC, Chen JY, Zhao JZ, He L et al. Surface characterization of titanium and adsorption of bovine serum albumin. Materials Characterizarion. 2003; 49:129-137. http://dx.doi.org/10.1016/ S1044-5803(02)00341-8

3. Eisenbarth E, Velten D, Muller M, Thull R and Breme J. Biocompatibility of -stabilizing elements of titanium alloys. Biomaterials. 2004; 25:5701-5713. PMid:15147816. http://dx.doi.org/10.1016/j. biomaterials.2004.01.021

4. Cheng $X$ and Roscoe SG. Corrosion behavior of titanium in the presence of calcium phosphate and serum proteins. Biomaterials. 2005; 26:7350-7356. PMid:16023203. http://dx.doi.org/10.1016/j. biomaterials.2005.05.047

5. Hollander DA, Walter MV, Wirtz T, Sellei R, Schimidt-Rohlfing B, Paar O et al. Structural, mechanical and in vitro characterization of individually structured Ti-6Al-4V produced by direct laser forming. Biomaterials. 2006; 27:955-963. PMid:16115681. http://dx.doi.org/10.1016/j. biomaterials.2005.07.041

6. Bignon A. Optimisation de la structure poreuse d'implants en phosphate de calcium pour application de complement osseux et relargage in situ d'un principe actif. [thesis]. Lyon : Institut National des Sciences Appliquées de Lyon ; 2002.

7. Zreiqat H, Valenzuela SM, Nissan BB, Roest R, Knabe C, Rradlanski $\mathrm{RJ}$ et al. The effect of surface chemistry modification of titanium alloy on signaling pathways in human osteoblasts. Biomaterials. 2005; 26:7579-7586. PMid:16002135. http://dx.doi.org/10.1016/j. biomaterials.2005.05.024

8. Jarcho M. Calcium phosphate ceramics as hard tissue prosthetics. Clinical Orthopaedics and Related Research. 1981; 157:259-78.

9. Salman S, Gunduz O, Yilmaz S, Oveçoglu L, Gookhale A, Agathopoulos $S$ et al. Sintering effect on mechanical properties of composites of natural hydroxyapatites and titanium. Ceramics International. 2009; 35(7):2965-2971. http://dx.doi.org/10.1016/j.ceramint.2009.04.004

10. Nath S, Tripathi $\mathrm{R}$ and Basu B. Understanding phase stability, microstructure development and biocompatibility in calcium phosphatetitania composites, synthesized from hydroxyapatite and titanium powder mix. Materials Science and Engineering. 2009; C29:97-107.

11. Ning $\mathrm{C}$ and Zhou Y. Correlations between the in vitro and in vivo bioactivity of the Ti/HA composites fabricated by a powder metallurgy method. Acta Biomaterialia. 2008; 4:1944-1952. PMid:18502711. http://dx.doi.org/10.1016/j.actbio.2008.04.015

12. Marcelo TM, Livramento V, De Oliveira MV and Carvalho MH. Microstructural Characterization and Interactions in $\mathrm{Ti}$-and $\mathrm{TiH}_{2}-$ Hydroxyapatite Vacuum Sintered Composites. Materials Research. 2006; 9:65-71. http://dx.doi.org/10.1590/S1516-14392006000100013

13. Ning CQ and Zhou Y. On the microstructure of biocomposites sintered from Ti,HA and bioactive glass. Biomaterials. 2004; 25:3379-3387. PMid:15020110. http://dx.doi.org/10.1016/j.biomaterials.2003.10.017
14. Ning CQ and Zhou Y. In vitro bioactivity of a biocomposite fabricated from HA and Ti powders by powder metallurgy method. Biomaterials. 2002; 23:2909-2915. http://dx.doi.org/10.1016/S0142-9612(01)00419-7

15. Chu C, Zhu J, Yin Z and Lin P. Optimal design and fabrication of hydroxyapatite_Ti asymmetrical functionally graded biomaterial. Materials Science and Engineering. 2003; A348:244-250.

16. Chu C, Zhu J, Yin Z and Lin P. Structure optimization and properties of hydroxyapatite-Ti symmetrical functionally graded biomaterial. Materials Science and Engineering. 2001; A316:205-210.

17. Chenglin C, Jingchuan Z, Zhongda Y and Shidong W. HydroxyapatiteTi functionally graded biomaterial fabricated by powder metallurgy. Materials Science and Engineering. 1999; A271:95-100.

18. Karanjai M, Sundaresan R, Mohan TRR and Kashyap BP. Evaluation of growth of calcium phosphate ceramics on sintered Ti-Ca-P composites. Materials Science and Engineering. 2008; C28:1401-1407.

19. Karanjai M, Sundaresan R, Rao GVN, Mohan TRR and Kashyap BP. Development of titanium based biocomposite by powder metallurgy processing with in situ forming of Ca-P phases. Materials Science and Engineering. 2007; A447:19-26.

20. Resende CX, Dille J, Platt GM, Bastos IN and Soares GA. Characterization of coating produced on titanium surface by a designed solution containing calcium and phosphate ions. Materials Chemistry and Physics. 2008;109:429-35. http://dx.doi.org/10.1016/j.matchemphys.2007.12.011

21. Gemelli E, Scariot A and Almeida Camargo NH. Thermal Characterization of Commercially Pure Titanium for Dental Applications. Materials Research. 2007; 10:241-246. http://dx.doi.org/10.1590/S151614392007000300004

22. Orzechowski LG, Almeida Camargo NH, Gemelli E, Feit G, Dalmônico GML and Melnik V. Elaboração e caracterização de biocimentos bifásicos de HA/TCP para aplicações como substitutos de tecido ósseo. $6^{\circ}$ Congresso Latino Americano de Órgãos Artificiais e Biomateriais; 2010; Gramado. Gramado; 2010. CDROM.

23. Melnik V, Almeida Camargo NH, Pinheiro D, Dalmônico GML, Orzechwski LG, Feit G et al. Síntese e caracterização de fosfatos de cálcio nanoestruturado para aplicações na ortopedia e na traumatologia. In: $6^{\circ}$ Congresso Latino Americano de Órgãos Artificiais e Biomateriais 2010; Gramado. Gramado; 2010. CDROM.

24. De Souza JCP. Estudo e caracterização de pós nanoestruturados de fosfatos de cálcio e nanocompósitos de fosfatos de cálcio/alumina-sol gel para aplicações biomédicas. [dissertação]. Joinville: Universidade do Estado de Santa Catarina; 2009. 100p.

25. Gemelli E, Resende CX and De Almeida Soares GD. Nucleation and growth of octacalcium phosphate on treated titanium by immersion in a simplified simulated body fluid. Journal of Materials Science: Materials in Medicine. 2010; 21:2035-2047. PMid:20390323. http://dx.doi. org/10.1007/s10856-010-4074-9 